ISSN 2236-0859

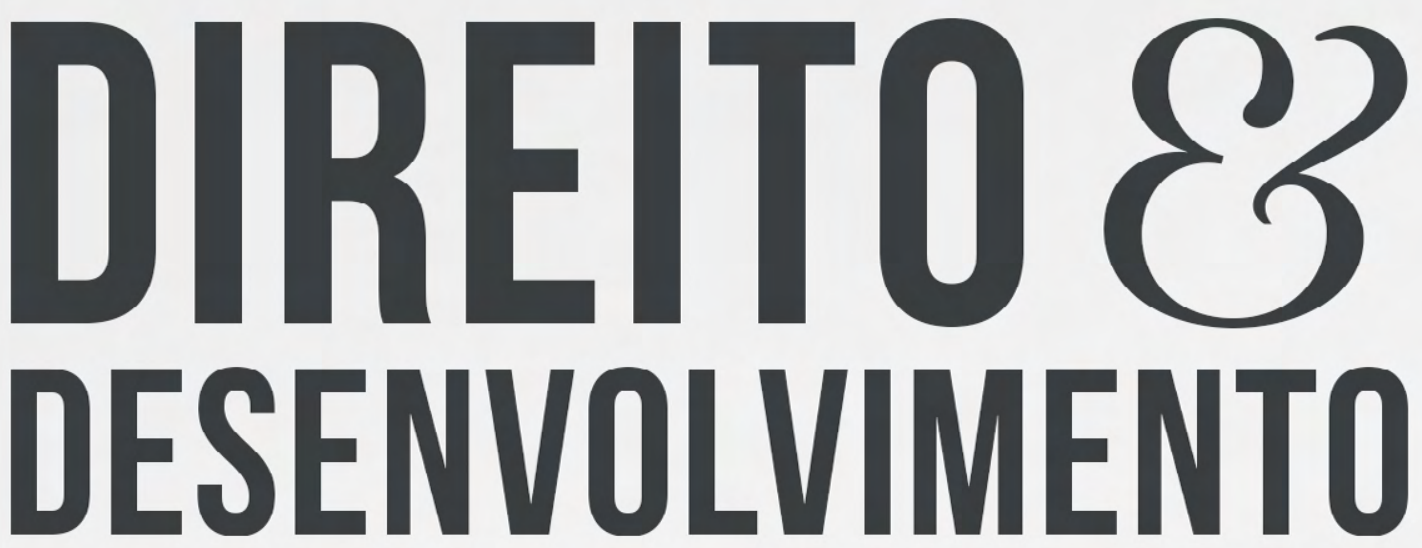

REVISTA DO PROGRAMA DE PÓS-GRADUAÇÃO EM DIREITO MESTRADO EM DIREITO E DESENVOLVIMENTO SUSTENTÁVEL

\title{
APOSENTADORIA POR IDADE DO TRANSGENEERO: DIREITOS DE PERSONALIDADE E O ACESSO Ä JUSTIÇA
}

\author{
DIRCEU PEREIRA SIQUEIRA \\ NAYANA LOUISE SAQUI PUPO
}




\title{
APOSENTADORIA POR IDADE DO TRANSGÊNERO: DIREITOS DE PERSONALIDADE E O ACESSO À JUSTIÇA
}

\author{
AGE RETIREMENT OF THE TRANSGENDER: \\ PERSONALITY RIGHTS AND ACCESS TO JUSTICE
}

Recebido: $16 / 10 / 2018$

Aprovado: 19/10/2018

\author{
Dirceu Pereira Siqueira* \\ Nayana Louise Saqui Pupo**
}

RESUMO: É certo que muito ainda há que debater acerca do direitos transexuais, precisamente sob a seara do Direito Previdenciário, quando se trata de concessão ou readequação de benefícios. O presente artigo visa debater sobre as questões de negativa de concessão do benefício de Aposentadoria por Idade, seja urbano ou rural, bem como a negativa de readequação de cadastro previdenciário do segurado transgênero. Pela tema em tela, há a existência de um amparo constitucional e infraconstitucional ao transexual, como por exemplo, o princípio da dignidade humana, os direitos fundamentais e os direitos de personalidade. Todavia, apesar destes arcabouçou, existe uma omissão legislativa em especial ao transgênero, ficando este indivíduo a mercê de decisões “inovadoras” judiciais, isto é, em completa situação de insegurança jurídica e social. Salienta-se que a metodologia aplicada, consubstanciou-se em uma pesquisa qualitativa, dada a análise de dado indutivos, isto é, se realizou uma análise descritiva do fenômeno discriminador do direito do transexual no Direito Previdenciário. Baseou-se também em uma pesquisa exploratória, na construção de hipóteses na solução da problemática existente, ora, a omissão legislativa, bem como em pesquisas explicativas na investida de identificar a motivação desses fenômenos e por fim, teve-se pesquisas bibliográficas, tais como artigo científicos dispostos em revistas jurídicas e livros.

Palavras-chave: Transgênero. Previdenciário. Aposentadoria por Idade. Direito de Personalidade. Acesso à Justiça.

\begin{abstract}
It is true that much still has to be discussed about transsexual rights, precisely under the Social Security Law, when it comes to granting or re-fitting benefits. This article aims to discuss the issues of refusal to grant the Retirement Benefit by Age, whether urban or rural, as well as the refusal to readjust the social security record of the transgender insured. Due to the current issue, there is a constitutional and infraconstitutional support for the transsexual, such as the principle of human dignity, fundamental rights and personality rights. However, in spite of these frameworks, there is a legislative omission in particular to the transgender, being this individual at the mercy of innovative judicial decisions, that is, in complete legal and social insecurity. It should be emphasized that the applied methodology consubstantiated in a qualitative research, given the analysis of inductive data, that is, a descriptive analysis of the discriminatory phenomenon of the right of the transsexual in the Social Security Law. It was also based on an exploratory research, on the construction of hypotheses in the solution of the existing problematic, or, the legislative omission, as well as on explanatory research in the invested to identify the motivation of these phenomena and, finally, bibliographical research

\footnotetext{
* Coordenador e Professor Permanente do Programa de Pós Graduação Stricto Sensu (Mestrado) em Direito no Centro Universitário de Maringá - PR (UniCesumar); Pós-doutor em Democracia e Direitos Humanos pelo Ius Gentium Conimbrigae da Faculdade de Direito da Universidade de Coimbra e pelo Centro de Estudos Interdisciplinares do Séc. XX da Universidade de Coimbra. E-mail: dpsiqueira@uol.com.br

** Mestranda em Ciências Jurídicas na linha de pesquisa de Instrumentos e Efetivação dos Direitos da Personalidade pelo Unicesumar; Especialista em Direito Previdenciário pela Universidade Estadual de Londrina. E-mail: nayana.pupo@gmail.com
} 
was done, such as scientific articles arranged in legal journals and books.

Keywords: Transgender. Social Security. Retirement by Age. Right of Personality. Access to justice.

\section{INTRODUÇÃO}

A discussão a ser desenvolvida pelo artigo em tela, consubstancia-se no cenário de muitos debates acerca do indivíduo transexual, precisamente, quando da solicitação de concessão do benefício previdenciário de Aposentadoria Por Idade. Salienta-se que estaremos a tratar aqui do regime geral de previdência (RGPS), tendo como seus segurados os empregados, empregados domésticos, contribuintes individuais, trabalhador avulso, especial e facultativo, não sendo assim, discutidos conteúdos de regimes próprios (RPPS), aqueles dos servidores públicos.

No mesmo seguimento, é preciso enaltecer que, a partir da premissa de que o Brasil é um Estado Democrático de Direito (SEN, 200o), tem-se que diante dos aspectos constitucionais, ora do direito a dignidade da pessoa humana e dos direitos fundamentais, deve-se combater qualquer existência de discriminação negativa as pessoas. Logo, pelo trabalho em tela, a discussão baseia-se na existência da discriminação do indivíduo transexual, no qual tenta se readequar à sociedade e também no cenário previdenciário.

E quando está a se falar de cenário previdenciário, é preciso compreender que a Previdência Social é um segmento da Seguridade Social, na qual visa estabelecer um sistema de proteção social. Nesse sentido, como bem pontua Savaris e Gonçalves (2018), existem duas formas de proteção, uma sendo a proteção civil, na qual visa a "garantia de liberdades fundamentais e asseguração dos bens e pessoas no contexto de um Estado democrático", e a outra sendo a proteção social, que é aquela que "oferece cobertura contra os principais riscos suscetíveis de gerar uma degradação da situação dos indivíduos”. Assim sendo, temos que as pessoas estão sempre abertas a eventos que lhe causem danos geradores de incapacitações e cessação de sua autonomia, ou seja, as pessoas percepcionam os riscos sociais, tais como, a extrema pobreza, o desemprego, uma doença, algum acidente, etc. Desta forma, sob a finalidade de combater esses riscos sociais é que se criam e implementam a políticas públicas de segurança social, e no estudo em específico, temos a Previdência Social.

Desta feita, temos que a Previdência Social é um mecanismo de proteção social, no qual consubstancia-se na condição de um vinculação ao sistema e a devida contribuição mensal para fins de carência e posterior acesso aos benefícios, isto é, para o indivíduo esteja vinculado ao sistema previdenciário, ele deve se filiar ao mesmo e realizar o pagamento de contribuições mensais, na quais ensejaram a qualidade de sujeito segurado que poderá usufruir dos diversos benefícios postos.

Ao artigo, nós interessa abordar apenas o benefício de Aposentadoria Por Idade, no qual se trata de um risco social em razão da cessação de atividade em virtude da idade do segurado. Logo, temos por este benefício duas possibilidades de concessão, uma sob o trabalhador de atividade urbana e outra sob o trabalhador de atividade rural.

Acerca destas possibilidades, temos alguns critérios a serem cumpridos, tais como, o etário, de gênero e de carência, no que tange a Aposentadoria por Idade Urbana, temos que o homem tem que ter 65 (sessenta e cinco) anos e a mulher 60 (sessenta) anos, relacionandose à Rural, o homem tem que ter 6o (sessenta) anos e a mulher 55 (cinquenta e cinco) anos. Não vem ao caso, esclarecer o critério de carência, pois conforme abordando anteriormente, 
o artigo consubstancia-se na ideia da existência de tratamento discriminador ao indivíduo transexual.

Assim, esclarecidos tais conceitos introdutórios, esclarece-se que a problemática reside na indagação de se saber se o direito previdenciário avançou proporcionalmente com o direito civil, no qual faz reconhecimento de pessoas transexuais em ter a capacidade civil. Além do mais, como fica a readequação da aposentadoria do indivíduo que se transforma? Há normas regulamentadoras sobre o tema? Existem precedentes? Como deverá a Autarquia Federal agir diante de uma alteração de sexo no meio de uma contribuição? Há violação à liberdade de acesso à justiça diante da impossibilidade de alteração? A alteração do nome social é direito pessoalíssimo? Há omissão legislativa?

Neste sentindo, na tentativa de responder a tais questionamentos, este trabalho irá realizar uma análise sob as perspectivas constitucionais, conforme exposto acima, sob o cenário do Direito Previdenciário, em especial ao benefício de Aposentadoria por Idade, seja rural ou urbana, como forma de garantia da liberdade do indivíduo transgênero, afastando-se a existência de qualquer discriminação.

Por fim, há que se destacar a metodologia utilizada, sendo que, pelo artigo realizouse através de uma metodologia de pesquisa qualitativa, tentando se explicar a motivação da discriminação existente em relação aos indivíduo transexuais; e descritiva no intuito de caracterizar e descrever o presente fenômeno discriminador. Não obstante, tem-se como procedimentos técnicos as pesquisas bibliográficas, tais como, artigos científicos de revistas jurídicas, livros, dissertações e/ou teses, nacionais ou estrangeiros; e documental mediante materiais eletrônicos disponibilizados por entidades.

\section{A TRANSEXUALIDADE}

De forma sintetizada é imperioso aclarar o conceito de indivíduo transexual, podendo ser interpretado como um indivíduo que fisicamente se apresenta em um sexo e psicologicamente em sexo oposto, situação esta que vem trazer inúmeras dificuldades na integração social, bem como em aceitação pessoal. Nesse sentindo, define Diniz, citando outros autores (1998, p. 604):

1. Aquele que não aceita o seu sexo, identificando-se psicologicamente com o sexo oposto (Hojda), sendo, portanto, um hermafrodita psíquico (H. Benjamin). 2. Aquele que, apesar de aparentar ter um sexo, apresenta constituição cromossômica do sexo oposto e mediante cirurgia passa para outro sexo (Othon Sidou). Tal intervenção cirúrgica para mulher consiste na retirada dos seios, fechamento da vagina e confecção de pênis artificial, e para o homem, na emasculação e posterior implantação de vagina (Paulo Matos Peixoto). 3. Para associação Paulista de Medicina, é o indivíduo com identificação psicossexual oposta aos seus órgãos genitais externos, com o desejo compulsivo de mudálos. 4. Aquele que, tendo morfologia genital masculina, sente-se psicologicamente mulher, rejeitando seu papel de 'gênero' masculino até buscar a alteração de sua anatomia para assumir aparência física feminina. Correspondentemente, há mulheres em situação análoga (Aldo Pereira).

Igualmente, explana Peres (2001, p. 125), que:

[...] o transexual apresenta um sintoma primordial consistente na inversão da identificação sexual. De forma clara, o que se quer dizer é que, sendo homem, identificase como mulher e, logicamente, no caso inverso, sendo mulher, identifica-se como homem. 
Conseguintemente, menciona Szaniawski (1999, p. 49) que os transexuais são: "indivíduos que apresentam, ao simples exame ocular, genitais externos do tipo masculino e são portadores de uma psique totalmente ou predominantemente feminina, e vice-versa."

Nesta ordem, é conveniente esclarecer que a transexualidade não é um fenômeno passageiro, é algo em que o indivíduo leva para o resto de sua vida, haja vista que este fato ocorre desde a tenra idade na maioria das circunstâncias. Logo, estamos a falar de um aspecto de perpetuidade da condição de conflito de psicológico, isto é, a pessoa não se torna transexual da noite para o dia e sim de um decorrer de tempo. Assim, enaltece Ramnsey (1998, p. 32), que esses indivíduos:

1. Buscam tratamento hormonal permanente e/ou cirurgia de redesignação sexual; 2. Completaram algumas fases de tratamento hormonal e/ou cirurgia de redesignação sexual, e estão satisfeitos com os resultados; 3 . Aspiram a um tratamento hormonal e/ ou a uma cirurgia de redesignação sexual, mas que - por razões religiosas, políticas, financeiras ou outras - não podem participar ativa, plena ou publicamente neste processo. Na minha experiência, transexualidade - ao contrário de um simples distúrbio de identidade de gênero - não é um fenômeno passageiro. Poderia antes ser descrito como 'imutável na maioria das instâncias'. (É também extremamente raro que psicoses se apresentem como transexualidade transparente). O processo transexual - a jornada que começa com uma terapia e vestir-se como o outro sexo, passa por tratamento hormonal e termina em cirurgia - não é um capricho passageiro. É a busca consistente de integração física, emocional, social, espiritual e sexual, conquistada a enormes penas pessoais. A vontade de ter seu sexo alterado é o ponto mais característico na psique do transexual. A doutrina reconhece que tal fato ocorre desde cedo. Suas vestes femininas, seus modos são femininos (e não afeminados). Trazem em seu mo de ser delicado um traço distintivo. São mais sensíveis e pretendem companhia do mesmo sexo (no exemplo, masculina, sempre mais velha e mais forte).

Nesse norte, há que se salientar que o indivíduo transexual, não deve ser confundido com outros gêneros, como por exemplo, homossexuais e/ou travestis, pois nestes dois casos não há o caráter de definitividade da situação de rejeição com a seu atual aspecto físico. Não obstante, os transexuais podem vir a ser homossexuais ou heterossexuais, isto é, ele podem tem afinidade tanto pela pessoa do mesmo sexo, quanto pelo sexo oposto, assim, podendo ou não ser homossexual. Ainda, neste seguimento, apesar do travesti ter uma identidade feminina, não existe uma necessidade e/ou incômodo com seu órgão genital, não se vislumbra uma necessidade de realizar uma cirurgia de transgenitalização.

Por consequência deste conflito interno constante no interior do sujeito, as ciências médicas trataram até 2018 a transexualidade como o transtorno de identidade de gênero, conforme Classificação Internacional de Doenças:

F64.o Transexualismo: Trata-se de um desejo de viver e ser aceito enquanto pessoa do sexo oposto. Este desejo se acompanha em geral de um sentimento de mal-estar ou de inadaptação por referência a seu próprio sexo anatômico e do desejo de submeter-se a uma intervenção cirúrgica ou a um tratamento hormonal a fim de tornar seu corpo tão conforme quanto possível ao sexo desejado.

Na ideia contra argumentativa, já se tinha a ótica de Peres (2001), no sentindo de que o transexual não deve ser tratado ou então, considerado como um doente mental, pois todo o contexto é permeado pela lucidez, não havendo, de certa forma, qualquer desordem psicótica da personalidade.

E corroborando com o exposto acima, aos 18 de Junho de 2018 a Organização Mundial da Saúde (OMS) lançou uma nova classificação internacional de doenças, com o CID-11, no 
qual será apresentado na Assembleia Mundial da Saúde em Maio de 2019 para adoção pelos Estados Membros e entrará em vigor no dia $1^{\circ}$ de Janeiro de 2022. Esse CID acaba por incluir novos capítulos, em especial sobre "saúde sexual", na qual abordará a questão do transexual de não ter classificação de doença mental e sim de incongruência de gênero (Lindmeier, 2018). E de acordo com o catálogo da instituição, a incongruência de gênero, em tradução livre:

[...] é caracterizada por um incongruência acentuada e persistente entre o sexo experiente de um indivíduo e o sexo atribuído. Comportamento variante de gênero e preferências por si só não são base para atribuir diagnósticos neste grupo.Observadas tais questões, não há que se considerar, de certa maneira, que o transexual é um indivíduo portador de um transtorno, pois como mencionado acima, este apresenta plena lucidez sobre o que são seus sentimentos, porém deve-se considerar a hipótese de cuidados significativos de saúde, por isso a necessidade de uma codificação do CID. Assim, são formas de tratamentos, as práticas de cirurgias, os tratamentos hormonais e a psicoterapia. Estes tratamentos são vistos com maus olhos perante a sociedade, entretanto a ótica vem sendo abandonada, mesmo porque, o Estado não tem como coibir ou reprimir a vontade das pessoas, haja vista que a democracia é parte integrante de uma sociedade.

A sociedade apresenta valores característicos que não podem ser ignorados, assim sendo, apesar de apresentar uma maioria com opinião prevalecente, encontra-se também uma minoria que deve ser reconhecida. Nesse sentindo dispõe Araújo (200o, p. 2 e 3):

A democracia é confirmada na valorização da maioria, sem o desprezo da minoria. Quando falamos em Estado Democrático, falamos da vontade majoritária, mas não da ditadura da maioria. [...]. Tolerar significa conviver, sem perder a própria convicção. A maioria continua prestigiada, convivendo com a minoria, respeitando-lhe os valores e as crenças.

Por esta análise, há que se falar em uma tolerância para que haja uma compatibilidade com o Estado democrático, pois a falta desta poderá causar prejuízos incalculáveis à humanidade, e em virtude disto, se presa um equilíbrio entre a vontade da maioria e a minoria, podendo esta ser acolhida sempre que possível, desde que não haja uma ameaça aos valores da maioria e assim, atingir um bem comum.

Logo, é evidente que o direito dos transexuais é um direito personalíssimo, tendo em vista que a sexualidade humana está contida no sentido de personalidade, sendo este, o elemento essencial e vital da pessoa. À vista disso, conclui-se que a opção sexual faz parte dos direitos intransmissíveis, indisponíveis e inalienáveis, dado que dentro do conjunto da personalidade do ser humano, se forma um conteúdo mínimo. Assim sendo, o direito do transexual relaciona-se ao direito à vida digna, à identidade, ao próprio corpo, à intimidade, à saúde, etc., sendo estes os direitos inerentes a personalidade humana.

Uma vez não observados os direitos da personalidade, especificamente ao transexual, haverá tremenda infelicidade deste, pois se verifica uma vida conflitiva, angustiante e difícil, isto é, a sua sensação de viver uma vida dupla que decorre da sua não-identificação sexual abarca um grau altíssimo de infelicidade e desequilíbrio.

Nesse sentindo, entendendo que o Estado tenha como objetivo a promoção do bem de todos, este acaba por seguir os princípios inerentes à nossa Constituição, garantindo-se assim, que o indivíduo atinja sua plenitude, enquanto ser humano, buscando sua felicidade, sua paz, sua integridade, o que de certa forma, nunca encontrou enquanto transexual.

Diante de todo o exposto, a busca pelas premissas constitucionais, significa permitir que o transexual busque sua própria felicidade, bem como a sua integração social sem preconceitos de origem, raça, sexo, cor, idade e quaisquer outras formas de discriminação. 


\section{DIREITOS DE PERSONALIDADE E O ACESSO À JUSTIÇA: ASPECTOS PARA CONCESSÃO/READEQUAÇÀO DE APOSENTARIA POR IDADE AO TRANSGÊNERO}

Diante dos questionamentos exposto em se introdutória, é preciso esclarecer o cerne do Direito de Personalidade, todavia, para que possamos chegar a este direito, é imperioso esclarecer alguns princípios anteriores.

Desta forma, é preciso enaltecer que através da Carta Magna, na qual norteia e concede diretrizes para o funcionamento de um Estado Democrático de Direito, temos um conjunto de normas, regras, princípios e leis, através da Constituição Federal de 1988, nos quais promovem direitos e deveres aos cidadãos e aos próprio Estado, no intuito de coibir qualquer lesão à norma suprema e aos princípios fundamentais (Siqueira e Nunes, 2018).

Assim, pela análise do indivíduo transexual, é preciso, a priori, esclarecer os aspectos do princípio constitucional da dignidade da pessoa humana, no qual segundo Espíndola (1998, p.76), possui como natureza:

[...] conteúdos primários diretores do sistema jurídico-normativo fundamental de um Estado. Dotados de originalidade e superioridade material sobre todo os conteúdos que formam o ordenamento constitucional, os valores firmados pela sociedade são transformados pelo Direito em princípios.

Sob este aspecto, tem-se baseado no referido princípio, o artigo $1^{\circ}$, inciso III $^{2}$ da Constituição Federal de 1988, no qual atribui um direito especial as pessoas, no sentindo de um respeito mútuo e digno, visando em não prejudicar a existência humana, isto é, possui a precípua finalidade de não desvalorizar os direitos fundamentais. Desta forma, conceitua Alexandre de Morais (2002, p. 128) que:

A dignidade é um valor espiritual e moral inerente à pessoa, que se manifesta singularmente na autodeterminação consciente e responsável da própria vida e que traz consigo a pretensão ao respeito por parte das demais pessoas, constituindo-se em um mínimo invulnerável que todo estatuto jurídico deve assegurar, de modo que, somente excepcionalmente, possam ser feitas limitações ao exercício dos direitos fundamentais, mas sempre sem menosprezar a necessária estima que merecem todas as pessoas enquanto seres humanos.

Deste modo, temos que a dignidade da pessoa humana, relaciona-se intrinsecamente com os direitos fundamentais, servindo assim, como um dos princípios mais importantes que norteia o direito moderno em virtude de um preceito fundamental para que haja o bem-estar social (Dworkin, 2002). Portanto, tem-se que a dignidade da pessoa humana é o valor básico de um Estado Democrático de Direito, reconhecendo-se o ser humano "como o centro e o fim do direito" (Awad, 2006, p. 113). Nesta continuidade, é contemplado o presente princípio pelos direitos fundamentais, como forma de princípio norteador dos demais, conforme exposto por Olsen (2006, p. 5):

Os direitos fundamentais sociais presentes na Constituição de 1988 têm sua fundamentalidade garantida no texto constitucional positivo e na sua relação com valores e objetivos estampados na carta constitucional, especialmente com a dignidade da pessoa humana. São normas de caráter predominantemente principiológico, que estabelecem obrigações prima facie de prestar algo, de modo que sua aplicação geralmente requer ponderação com bens jurídicos ou direitos em sentido contrário, mediante análise da

2 Art. o A República Federativa do Brasil, formada pela união indissolúvel dos Estados e Municípios e do Distrito Federal, constituise em Estado Democrático de Direito e tem como fundamentos: [...] III - a dignidade da pessoa humana; 
proporcionalidade. Ao demandarem do Estado prestações materiais, têm um inegável conteúdo econômico, que acaba por influenciar sua efetividade

Assim, temos pelos direitos fundamentais, aqueles direitos essenciais a cada indivíduo, podendo estes serem um elemento identificador do princípio da dignidade da pessoa humana, com objetivo de "colocar o Estado brasileiro ao serviço dos cidadãos, visto que o Estado tão somente existe em função da pessoa humana, ainda na medida de sua soberania, e não o contrário" (Siqueira e Nunes, 2018, p. 58).

Após tais esclarecimento, se faz a análise do Direito de Personalidade, que há muito é confundido com os direitos fundamentais. Logo, é preciso fazer algumas distinções entre os mesmo, todavia, salienta-se que ambos podem se complementar. A distinção se baseia na ideia do direito positivo em o direito fundamental em um direito público e o direito de personalidade de um direito privado. Nesse sentindo, conceitua Coimbra e Quaglioz (2007, p. 9) que os direitos de personalidade:

[...] são aqueles que conferem às pessoas o poder de proteger as características mais relevantes de sua personalidade e, sem os quais, esta se tornaria algo insuscetível de realização, tendo sua existência impossibilitada; são direitos subjetivos, cujo conteúdo se identifica com os valores e bens essenciais da pessoa humana, abrangendo aspectos morais, intelectuais e físicos. Afastam-se dos direitos patrimoniais, e existem a par destes, exatamente por serem despidos de conotação econômica intrínseca.

Conforme aludido, é o direito de personalidade aquele direito intrínseco ao ser humano, no qual tem por objetivo a proteção do indivíduo, de suas características e qualidades (Cardin e Benventuro, 2013). Nesse sentindo, na esfera constitucional, pelo princípio da dignidade da pessoa humana e dos princípios do artigo $5^{\circ}$, caput, ${ }^{3}$ temos a promoção e defesa deste direito.

No que tange a esfera infraconstitucional, nos é pertinente constar o Capítulo II do Código Civil Brasileiro (Lei no 10.406/2002), dos artigos 11 ao 21, no qual demonstra parâmetros principiológicos acerca do direito personalíssimo, isto é, não sendo este direito uma matéria exaustiva (Coimbra e Quaglioz, 2007). Desta feita, temos que o Direito de Personalidade constitui o valor mais elevado da pessoa humana, sendo inadmissível qualquer violação a si.

Assim sendo, quando estamos a falar do direito de se "transformar", ora, de realizar uma cirurgia de transgenitalização, estamos a falar do direito da pessoa de ser como ela é, ou seja, de um direito em que não fala em lesão a terceiros e/ou uma maioria. Temos que a personalidade é o que dá a identidade do indivíduo, como o nome, o sexo, as aparências, etc., é ela uma situação de identificação do ser como ele é, ou então, como ele deseja ser ou como se sente. Corrobora com isto o disposto por Choeri (2010, p. 135), que a: "identidade sexual, como integrante da identidade humana, compartilhando desse mesmo interesse existencial, deve ser igualmente tutelada e constituir, assim, objeto de direito subjetivo de personalidade".

Deste panorama, é preciso garantir o direito de alteração do gênero ao indivíduo, como forma de se garantir o princípio da igualdade e assim, a concretização de garantia de um direito personalíssimo e da dignidade da pessoa humana. Logo, podemos enquadrar este grupo em condição de vulnerabilidade perante uma coletividade, não tão somente, mas também perante ao Estado em si, pois quando estamos a tratar de uma tutela, precisamente, da Autarquia Previdenciária, inexiste uma previsão legislativa e procedimental específica.

Diante do exposto, presentes as falhas legislativas e procedimental de tutela dos direitos dos transexuais, perante à Autarquia Previdenciária, há que se questionar: existe violação à liberdade de acesso à justiça diante de omissão legislativa?

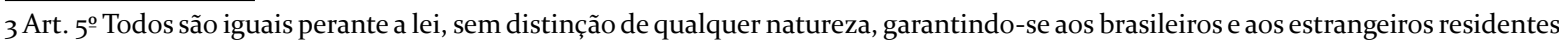
no País a inviolabilidade do direito à vida, à liberdade, à igualdade, à segurança e à propriedade, [...]. 
É evidente que haja uma relevante violação, pois em muito são negadas as concessões ou readequações aos benefício de Aposentadoria Por Idade, por não haver o indivíduo, condições físicas conforme o estabelecido social e juridicamente, consequentemente, não se tendo condições de igualdade e justiça (Siqueira e Nunes, 2018).

Desta forma, há que observar a questão atinente ao Acesso à Justiça, sendo este a garantia de um direito fundamental, no sentindo de se atribuir um tratamento igualitário jurídico a todos. É nesse viés que podemos atribuir a questão do transexual de readequar sua aposentadoria, seja diante de uma via administrativa ou judicial. A questão em si é que esse direito é garantia humanizada na construção de uma sociedade justa, bem como um direito de se postular uma tutela jurisdicional adequada e efetiva perante os órgãos do Poder Judiciário, conforme disposto no artigos $3^{\circ}$, incisos I e IV ${ }^{4}$ e $5^{\circ}$, inciso XXXV5 da Constituição Federal de 1988.

Nesse sentindo, o procedimento administrativo em via de regra, acaba obedecendo o padrão de negativa de concessão do benefício, em virtude de se encontrar o individual em outra condição de gênero. Não obstante, muito dificultoso se torna a atualização cadastral do segurado, sendo-lhe criado diversos empecilhos para a comprovação do atual gênero do mesmo. Assim, acaba o segurado tendo que recorrer ao procedimento judicial, ora mais lento, para que se veja ressalvado e garantido seu direito previdenciário.

No Brasil ainda inexistem precedentes acerca do tema, mas sob a perspectiva internacional, existe o exemplo exposto por Fernandes (2010) do Reino Unido, em que uma mulher trangênero fora impedida do direito de se aposentar na idade mínima exigida, ora 6o (sessenta) anos, e isto fez com que a Corte Europeia de Direitos Humanos reconhecesse a violação e permitisse a concessão do benefício da aposentadoria a esta. Deste cenário, é possível constar importância que o Poder Judiciário tem em resguardar esses direitos, haja vista a ausência de reconhecimento perante a Autarquia Previdenciária. Nesse sentindo, aclaram Ventura e Schramm (2009, p. 83) que:

\footnotetext{
É importante ressaltar que a alteração do sexo legal não é trivial para o sistema legal, que reconhece alguns direitos e obrigações diferenciadas para homens e mulheres, como a prestação de serviço militar obrigatório, tempo de aposentadoria, e outras relativas aos direitos de família, como maternidade e paternidade, filiação, casamento, que podem atingir direitos de terceiros
}

Diante do elucidado, é conflituosa a questão de que como o Estado tutela o direito à mudança de sexo, bem como o direito e dever de acordo com o sexo, podem gerar barreiras às a concessão ou readequação de direitos precisamente previdenciários? Assim, há que se compreender que "da mesma forma como ocorre com outros órgãos, na Previdência Social o transexual deve contrair e assumir todos os direitos e deveres de seu gênero”. (Lopes, 2015, p. 16).

Neste viés, a realidade prática é que os indivíduos transgêneros estão em total desamparo legislativo, trazendo à tona a questão de insegurança jurídica e desrespeito ao princípio constitucional da dignidade da pessoa humana, da liberdade, de direitos fundamentais e precisamente de tutela ao direito de personalidade.

Segundo Quadrini e Venazzi (2016, p. 47), essa omissão legislativa brasileira é atribuída aos legisladores, ficando apenas as doutrinas e as jurisprudências, o encargo de preencherem as lacunas existentes, para que assim:

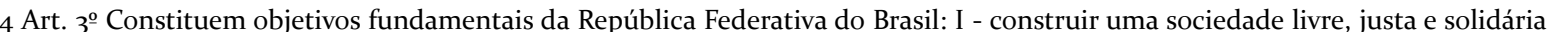
[...]IV - promover o bem de todos, sem preconceitos de origem, raça, sexo, cor, idade e quaisquer outras formas de discriminação.

5 XXXV - a lei não excluirá da apreciação do Poder Judiciário lesão ou ameaça a direito; 
[...] os transexuais tenham acesso aos direitos garantidos pela Constituição, como qualquer outro cidadão. Destarte, utilizam-se como fundamentos à concessão da aposentadoria ao transexual mediante o preenchimento dos requisitos correspondentes ao gênero sexual a que este se adequou, o direito à vida, à integridade física, à saúde, bem como o princípio da igualdade e da dignidade humana.

Ainda neste seguimento, é preciso destacar que a concessão de benefício previdenciário subsiste na mantença da própria existência humana, isto é, como medida de sobrevivência de indivíduo que não tenha outra forma de renda. Nesse sentido, negar a concessão ou readequação de benefício previdenciário, é lesionar o preceito constitucional do artigo $7^{\circ}$, inciso $\mathrm{XXX}^{6}$ da Constituição Federal de 1988 e artigo $1^{\circ}$ da Lei no 9.029/957. Isto posto, é "indispensável estabelecer um esquema que ofereça proteção em todos os aspectos, (...), de modo que as organizações devam assumir a responsabilidade em combater a discriminação aos transgêneros". (Siqueira e Nunes, 2018, p. 62).

Desta forma, conclui-se que apesar de se ter previsões de garantias constitucionais para o indivíduo transgênero, bem como uma tutela internacional acerca do mesmo, existem ainda grande omissões legislativas, ensejando inseguranças jurídica e social. Assim, se faz de suma importância a positivação e adequação pertinente ao tema com o tratamento igualitário destes indivíduos, haja vista que todas discussões e disposições atuais do tema, ficam a encargo do próprio judiciário, ensejando assim um ativismo judicial.

\section{CONSIDERAÇÕES FINAIS}

Conforme explanado na presente pesquisa, o Estado Democrático de Direito busca o bem comum para todos, isto é, a vida em sociedade tem como objetivo trazer a felicidade e o bem-estar de seus indivíduos. Assim, para que haja essa plenitude, há que se falar em tolerância, sendo esta a maneira mais justa e correta de se entender a problemática do transexual.

Nesse sentindo, fora constatado que é preciso garantir o direito de alteração do gênero ao indivíduo, como forma de se garantir o princípio da igualdade e assim, a concretização de garantia de um direito personalíssimo e da dignidade da pessoa humana. Logo, enquadrou-se este grupo em condição de vulnerabilidade perante uma coletividade, mas também perante ao Estado em si, pois quando estamos a tratar de uma tutela, precisamente, da Autarquia Previdenciária, inexiste uma previsão legislativa e procedimental específica.

Neste viés, a realidade prática é que os indivíduos transgêneros estão em total desamparo legislativo, trazendo à tona a questão de insegurança jurídica e desrespeito ao princípio constitucional da dignidade da pessoa humana, da liberdade, de direitos fundamentais e precisamente de tutela ao direito de personalidade.

É preciso destacar que a concessão de benefício previdenciário subsiste na mantença da própria existência humana, isto é, como medida de sobrevivência de indivíduo que não tenha outra forma de renda. Logo, a não concessão ou readequação do mesmo é situação violadora à dignidade da pessoa humana, bem como de preceitos garantidores da constituição de federal.

Desta forma, conclui-se que apesar de se ter previsões de garantias constitucionais para o indivíduo transgênero, bem como uma tutela internacional acerca do mesmo, existem ainda grande omissões legislativas, ensejando inseguranças jurídica e social. Assim, se faz de suma

6 Art. $7^{0}$ São direitos dos trabalhadores urbanos e rurais, além de outros que visem à melhoria de sua condição social: [...]XXX proibição de diferença de salários, de exercício de funções e de critério de admissão por motivo de sexo, idade, cor ou estado civil; 7 Art. $1^{\circ}$ É proibida a adoção de qualquer prática discriminatória e limitativa para efeito de acesso à relação de trabalho, ou de sua manutenção, por motivo de sexo, origem, raça, cor, estado civil, situação familiar, deficiência, reabilitação profissional, idade, entre outros, ressalvadas, nesse caso, as hipóteses de proteção à criança e ao adolescente previstas no inciso XXXIII do art. $7^{\circ}$ da Constituição Federal. 
importância a positivação e adequação pertinente ao tema com o tratamento igualitário destes indivíduos, haja vista que todas discussões e disposições atuais do tema, ficam a encargo do próprio judiciário, ensejando assim um ativismo judicial.

\section{REFERÊNCIAS}

ARAUJO, Luiz Alberto David. A Proteção Constitucional Do Transexual. São Paulo: Saraiva, 2000.

AWAD, Fahd. O Princípio Constitucional da Dignidade da Pessoa Humana. Revista Justiça do Direito. Passo Fundo, v. 20. N. 1, p. 111-120, 2006.

BENVENUTO, Fernanda Moreira. CARDIN, Valéria Silva Galdino. Do Reconhecimento dos Direitos dos Transexuais Como um dos Direitos da Personalidade. Revista Jurídica Cesumar - Mestrado. v. 13. n. 1. p. 113-130, jan/jun, 2013.

BRASIL. Classificação Internacional de Doenças e Problemas Relacionados à Saúde. Disponível em: <http://www.cremesp.org.br/pdfs/cidı_ultimaversaodisponivel_2012.pdf>. Acesso em: 11 jul. 2017.

.Constituição (1988). Emenda Constitucionalnº 91,19 defevereirode 2016. Diário Oficial.

Disponível em: <http://www.planalto.gov.br/ccivil_03/constituicao/constituicaocompilado. htm>. Acesso em: o1 set. 2016.

COIMBRA, Clarice Helena de Miranda; QUAGLIOZ, Flaviano Ribeiro. Direitos Fundamentais e Direito da Personalidade. Revista eletrônica da Faculdade de Direito de Campos. Campos dos Goytacazes, Rio de Janeiro, v. 2, n. 2, Abr. 2007. Disponível em: <http://bdjur.stj.jus.br// dspace/handle/2011/18139>. Acesso em: 15 out. 2018.

DINIZ, Maria Helena. Transexual, in dicionário jurídico, v. 4. São Paulo: Saraiva, 1998.

DWORKIN, R. Levando os Direitos a Sério. São Paulo: Martins Fontes, 2002.

ESPÍNDOLA, Ruy Samuel. Conceito de Princípios Constitucionais. São Paulo: Revista dos Tribunais, 1998.

FERNANDES, E.B.D. O Transexual e a Omissão da Lei: Um Estudo De Casos Paradigmáticos. Caderno Virtual, n. 21, v. 1 - Jan-Jun/2010.

LINDMEIER, Christian. WHO releases new International Classification of Diseases (ICD 11). World Health Organization. Disponível em: $<$ http://www.who.int/health-topics/internationalclassification-of-diseases>. Acesso em: 04 jul. 2018.

LOPES, A.L.M.D. O Direito à Identidade de Gênero e ao nome Civil dos Transexuais: Uma Análise Do Atual Cenário e da Necessidade de Adequação das Normas Brasileiras. Trabalho de Conclusão de Curso apresentado como requisito parcial para obtenção do grau de Bacharel em Ciências Jurídicas e Sociais pela PUC/RS. Porto Alegre, 2015. 
MORAES, Alexandre de. Constituição do Brasil Interpretada e Legislação Constitucional. São Paulo: Atlas, 2002. p. 128.

PERES, Ana Paula Ariston Barion. Transexualismo: O direito a uma nova identidade sexual. Rio de Janeiro: Renovar, 2001.

QUADRINI, M.C.J; VENAZZI, K.F. O Direito Previdenciário dos Transexuais: Percepção dos benefícios de aposentadoria por tempo de contribuição e por idade. ROMED, v. 2, n. 2016.

RAMSEY, Gerald. Transexuais: Perguntas e respostas. São Paulo: GLS, p. 32, 1998.

SAVARIS, José Antônio. GONÇALVES, Mariana Amelia Flauzino. Compêndio de Direito Previdenciário. Curitiba: Alteridade Editora, 2018.

SEN, Amartya Kumar. Desenvolvimento como liberdade. Trad. Laura Teixeira Motta. São Paulo: Companhia das Letras, 2000.

SIQUEIRA, Dirceu Pereira. NUNES, Danilo Henrique. O Transgênero e o Direito Previdenciário: Omissão legislativa e insegurança jurídica no acesso aos benefícios. Revista Jus Poiesis. Rio de Janeiro, v. 21, n. 25, 2018, p. 50-67. 29 de abr/2018. Disponível em: <http:// revistaadmmade.estacio.br/index.php/jurispoiesis/article/viewFile/5022/2330.> Acesso em: 15 out. 2018.

CASTRO, Lorenna Roberta Barbosa. Minorias e grupos vulneráveis: a questão terminológica como fator preponderante para uma real inclusão social. Revista Direitos Sociais e Políticas Públicas - Unifafibe. v. 5, n. 1, 2017.

SZANIAWSKI, Elimar. Limites e Possibilidades do Direito de Redesignação do Estado Sexual. São Paulo: Editora RT, 1999.

VENTURA, M; SCHRAMM, F.R. Limites e Possibilidades do Exercício da Autonomia nas Práticas Terapêuticas de Modificação Corporal e Alteração da Identidade Sexual. Physis Revista de Saúde Coletiva, Rio de Janeiro, 2009.

WOLF, Guilherme Eidelwein; BUFFON, Marciano. Custeio da seguridade social no Brasil: a controvérsia acerca do suposto déficit previdenciário. Revista Direitos Sociais e Políticas Públicas - Unifafibe. v. 5, n. 1, 2017. 